\title{
When Every Second Counts: Novel Device to Shorten Chest Tube Insertion Time in a Pre-hospital Setting
}

\author{
Ariel Drori · Yoav Kan-tor · Bettina Nadorp · Chen Goldstein ·
}

Amnon Buxboim • Yaakov Nahmias · Liran Levy

Received: August 3, 2016 / Published online: September 23, 2016

(C) The Author(s) 2016. This article is published with open access at Springerlink.com

\section{ABSTRACT}

Tension pneumothorax is a life-threatening medical emergency mostly associated with chest trauma. It is considered a leading cause of death due to injury and represents a substantial portion of potentially preventable deaths in the battlefield. The accepted therapeutic approach is manual thoracostomy with chest tube insertion. This is a relatively simple procedure when performed by skilled hands and in optimal conditions. In

Enhanced content To view enhanced content for this article go to http://www.medengine.com/Redeem/ 4E76F0606035D6AA.

A. Drori $(\bowtie)$

Internal Medicine Department, Hadassah-Hebrew

University Medical Center, Jerusalem, Israel

e-mail: arieldr@hadassah.org.il

Y. Kan-tor · B. Nadorp · A. Buxboim - Y. Nahmias Alexander Grass Center for Bioengineering, School of Computer Science and Engineering, The Hebrew University of Jerusalem, Jerusalem, Israel

C. Goldstein

The Jerusalem School of Business Administration, The Hebrew University of Jerusalem, Jerusalem, Israel

L. Levy

Institute of Pulmonary Medicine, Hadassah-Hebrew

University Medical Center, Jerusalem, Israel the battlefield and in other pre-hospital settings or when performed by unprofessional personnel, it may become complicated and time-consuming. We describe a novel technique for the treatment of pneumothorax in the pre-hospital setting, utilizing a quick, one-handed, easy-to-apply approach.

Keywords: Chest tube; Device; Pneumothorax; Pre-hospital; Trauma

\section{INTRODUCTION}

Chest tubes are indwelling catheters placed into the pleural space to evacuate abnormal collections of air or fluids that always represent chest pathology. The most frequent indications for tube thoracostomy are pneumothorax, pleural effusion, chylothorax, empyema, trauma, and postsurgical management after pulmonary and/or cardiac surgery [1]. Although there is a wide variety of chest tubes available on the market, they all share a common mechanism of operation: (1) a skin incision is made; (2) a tract in the subcutaneous tissue is bluntly dissected; (3) 
the tract is manually extended to enable insertion of the chest tube; (4) the chest tube is then advanced through and into the thoracic cavity; (5) the tube is then connected to a drainage device and secured with stitches [2].

Trauma is the leading cause of death among Americans between ages 1 and 46 years and the third cause of death overall [3]. It is estimated that thoracic trauma accounts for about $20-25 \%$ of all deaths resulting from trauma [4], with tension pneumothorax occurring in approximately 1 of 20 major trauma patients, although estimates of its incidence vary widely from $<1$ to $30 \%$ [5]. In out-of-hospital settings, needle decompression often appears to be an effective, easy-to-use and relatively safe method to treat tension pneumothorax; however, it is only a temporary strategy as occlusion may occur secondary to blood, particulate matter, kinking or tissue entrapment $[5,6]$. Chest tube placement is currently the definitive treatment for traumatic pneumothorax, but this technique is more time-consuming than other methods and requires trained personnel as well as a controlled setting in order to be safely applied. We describe here an experimental novel technique for chest tube placement. This experiment was conducted on a swine model.

\section{METHODS}

\section{Technique}

The device was developed to allow the placement of a chest tube in a quick, one-handed, easy-to-apply manner. The device includes two plates that are connected by hinges so that there are two configurations-a closed figuration (Fig. 1a) and an open configuration (Fig. 1b). After a small incision is made in the skin, the operator uses the device to bluntly dissect through the subcutaneous tissue until the pleural space is reached (Fig. 2a). After penetration, the device is activated, and a configuration change occurs, from closed to open (Fig. 2b). In its open configuration a portal is created, through which a standard silicon tube is inserted for proper drainage (Fig. 2c). After the chest tube is positioned, the device is removed, leaving the chest tube in place (Fig. 2d).

\section{Experimental Model}

An in vivo pilot experiment on a swine model to establish a proof-of-concept was successfully carried out (Fig. 3). We used the porcine model to simulate chest drain placement using the ThoraXS device. We first performed a $1-\mathrm{cm}$ incision in the chest wall, then inserted the device in its closed configuration through the incision. Once positioned in the pleural space, the device was activated, easily expanding inside the chest wall tissue, and a $20 \mathrm{Fr}$ silicone tube was inserted into the pleural space. This procedure was repeated three times at separated anatomical sites within the chest wall to ensure consistency of the results. (See 'Enhanced Content' link below abstract for video demonstration of procedure.)

\section{Compliance with Ethics Guidelines}

All institutional and national guidelines for the care and use of laboratory animals were followed.

\section{RESULTS}

On gross observation, we found that tissue penetration with the device in its closed configuration was carried out easily, overcoming tissue resistance. Expanding the 
Fig. 1 The ThoraXS device basic components. Two plates connected by hinges. a Closed configuration, b open configuration

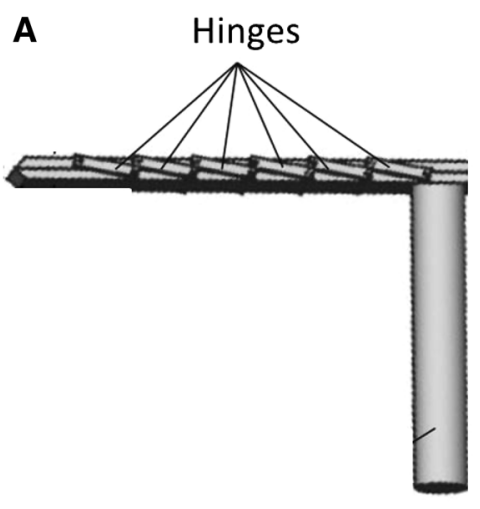

B
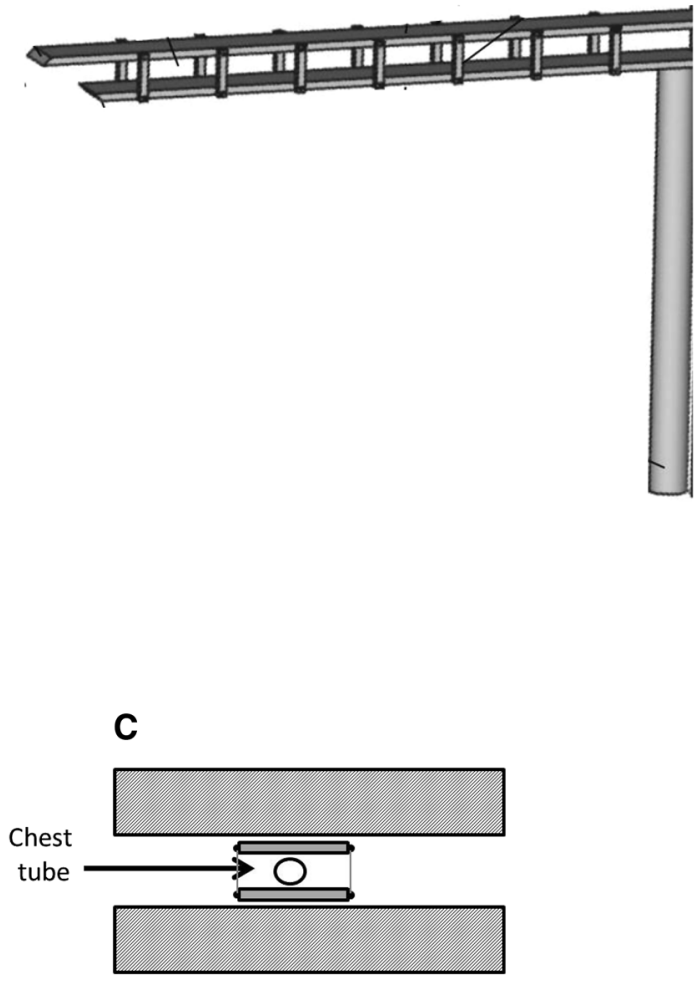

D

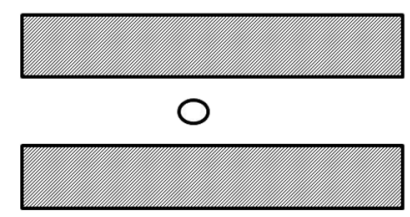

Fig. 2 Front view showing the ThoraXS insertion technique. The device is inserted through the chest wall in its closed configuration (a) and is then activated to change to its open configuration, thereby creating a portal for the

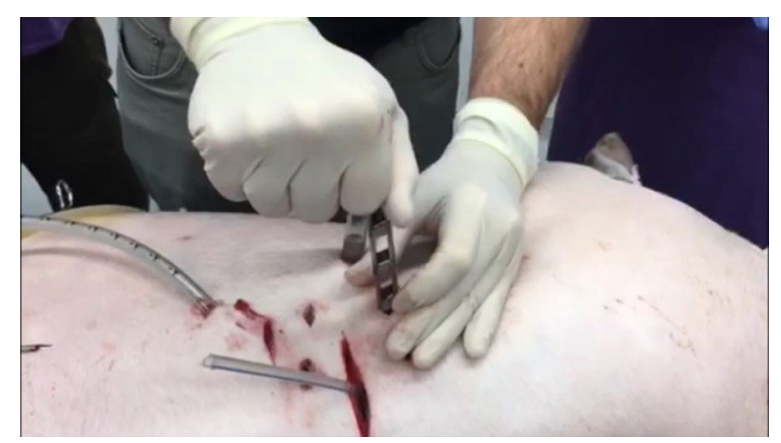

Fig. 3 An in vivo pilot experiment on a swine model Photo: Dr. Ariel Drori insertion of a chest tube (b). A silicone tube is then positioned (c), and the device is removed, leaving the chest tube in place $(\mathbf{d})$

device to its open configuration did not require outstanding force and was done smoothly using one hand. The device did not collapse back to its closed configuration, and its hinges resisted the tissue recoil without any problems. Insertion of the silicone tube through the device into the pleural space was easily performed. We did not encounter any significant bleeding or damage to adjacent internal organs. 


\section{DISCUSSION}

In an injured patient, chest tube insertion may be lifesaving. It facilitates the evacuation of fluids, prevents the development of tension pneumothorax or tamponades and promotes lung re-expansion while improving respiratory function [7]. In civilian trauma practice, the American College of Surgeons recommends needle decompression of tension pneumothoraces at the second intercostal space in the midclavicular line during the primary survey. This should be immediately followed by formal chest tube placement, with placement of a large-bore catheter [8]. However, the use of this approach seems to have developed in the absence of a sound evidence base for efficacy and was probably advocated and has been used widely because of ease of access. This approach is time-consuming, requires training and expertise and has a high failure rate, both inside and outside of the hospital setting [9, 10]. An alternative approach beyond the conventional one is definitely needed. The ThoraXS device was designed to provide a safer, blade-free, rapid and easy-to-use method for chest tube insertion, and we believe it has the potential to revolutionize the way chest trauma patients are managed. Patients with an indication for chest tube placement present in several ways-while some have clear clinical indications for immediate chest tube insertion (respiratory or hemodynamic instability/penetrating chest wound injury), others present with a degree of stability that allows the physician to seek optimal conditions. The use of the ThoraXS device, if proven effective, would potentially facilitate pre-hospital treatment of tension pneumothorax, replacing the ineffective needle decompression method. Moreover, the ThoraXS device may impact the threshold for intervention towards pre-hospital chest tube placement even in more stable patients that bear a clear indication for chest tube. It may also prove to be efficacious for the management of different pathologies as it can be easily positioned facing the lung apex for ideal drainage of air (in case of pneumothorax) or otherwise facing the lung base for a more effective drainage of blood (in case of hemothorax). Its unique structure and mechanism of action makes it easy to apply to patients of different body sizes and ages (pediatric and adults).

Our clinical experience with the device is still limited, and essential information on the operating characteristics and reliability of the device are yet to be determined. Nevertheless, our main aim at the current stage of development is proof of concept. Further experiments and clinical trials are required to support the superiority of the ThoraXS device over conventional chest tube insertion in terms of safety and efficacy. Similar to the conventional chest tube insertion technique, use of the ThoraXS device carries a potential risk of injuring intercostal and intrathoracic vasculature, as well as internal organs in the chest or abdomen. It is essential that medical teams receive proper training that focuses on general peri-procedural, operative, and safety-oriented aspects before attempting to use the device.

The device is currently in its final design and development stage. Our next step is to conduct a larger-scale pre-clinical trial in an animal model, and then proceed to a clinical trial. The safety profile, efficacy and healthcare economic benefit remain to be demonstrated.

\section{CONCLUSIONS}

As chest tube insertion in pre-hospital setting can be challenging, we believe that the ThoraXS device has the potential to change the way we 
treat trauma victims today, ensuring that every chest trauma patient will receive the appropriate treatment in a timely manner, prior to his arrival to a medical center.

\section{ACKNOWLEDGMENTS}

No funding or sponsorship was received for this study or publication of this article. All named authors meet the International Committee of Medical Journal Editors (ICMJE) criteria for authorship for this manuscript, take responsibility for the integrity of the work as a whole and have given final approval for the version to be published.

Disclosures. Ariel Drori is the founder of ThoraXS, which develops a device for the treatment of pneumothorax (patent pending). Chen Goldstein is employed by ThoraXS, Yoav Kan-tor, Bettine Nadorp, Amnon Buxboim, Yaakov Nahmias and Liran Levy declare no conflict of interest.

Compliance with Ethics Guidelines. All institutional and national guidelines for the care and use of laboratory animals were followed.

Open Access. This article is distributed under the terms of the Creative Commons Attribution-NonCommercial 4.0 International License (http://creativecommons.org/licenses/ by-nc/4.0/), which permits any noncommercial use, distribution, and reproduction in any medium, provided you give appropriate credit to the original author(s) and the source, provide a link to the Creative Commons license, and indicate if changes were made.

\section{REFERENCES}

1. Zardo P, Busk H, Kutschka I. Chest tube management: state of the art. Curr Opin Anaesthesiol. 2015;28(1):45-9.

2. Havelock T, Teoh R, Laws D, Gleeson F, Group BTSPDG. Pleural procedures and thoracic ultrasound: British Thoracic Society Pleural Disease Guideline 2010. Thorax. 2010;65[2]: ii61-76.

3. Centers for Disease Control and Prevention NCfIPaC. Web-based Injury Statistics Query and Reporting System (WISQARS). Available at: http:// www.cdc.gov/injury/wisqars. Accessed 22 May 2016.

4. Mancini MC. Blunt chest trauma. Available at: http://emedicine.medscape.com/article/428723overview. Accessed 22 May 2016.

5. Wernick B, Hon HH, Mubang $\mathrm{RN}$, et al. Complications of needle thoracostomy: A comprehensive clinical review. Int J Crit Illn Inj Sci. 2015;5(3):160-9.

6. Leigh-Smith $\mathrm{S}$, Harris T. Tension pneumothoraxtime for a re-think? Emerg Med J. 2005;22(1):8-16.

7. Kwiatt M, Tarbox A, Seamon MJ, et al. Thoracostomy tubes: a comprehensive review of complications and related topics. Int J Crit Illn Inj Sci. 2014;4(2):143-55.

8. Beckett A, Savage E, Pannell D, Acharya S, Kirkpatrick A, Tien HC. Needle decompression for tension pneumothorax in Tactical Combat Casualty Care: do catheters placed in the midaxillary line kink more often than those in the midclavicular line? J Trauma. 2011;71[5 Suppl 1]:S408-12.

9. Waydhas C, Sauerland S. Pre-hospital pleural decompression and chest tube placement after blunt trauma: a systematic review. Resuscitation. 2007;72(1):11-25.

10. Harris A, O'Driscoll BR, Turkington PM. Survey of major complications of intercostal chest drain insertion in the UK. Postgrad Med J. 1012; 2010(86):68-72. 